\title{
Comparison of Far-Field Noise for Three Significantly Different Model Turbofans
}

\author{
Richard P. Woodward ${ }^{*}$ \\ NASA Glenn Research Center, Cleveland, Ohio 44135
}

\begin{abstract}
Far-field noise sound power level (PWL) spectra and overall sound pressure level (OASPL) directivities were compared for three significantly different model fan stages which were tested in the NASA Glenn $9 \times 15$ Low Speed Wind Tunnel. The test fans included the Advanced Ducted Propulsor (ADP) Fan1, the baseline Source Diagnostic Test (SDT) fan, and the Quiet High Speed Fan2 (QHSF2) These fans had design rotor tangential tip speeds from 840 to $1474 \mathrm{ft} / \mathrm{s}$ and stage pressure ratios from 1.29 to 1.82. Additional parameters included rotor-stator spacing, stator sweep, and downstream support struts. Acoustic comparison points were selected on the basis of stage thrust. Acoustic results for the low tip speed/low pressure ratio fan (ADP Fan1) were thrust-adjusted to show how a geometricallyscaled version of this fan might compare at the higher design thrust levels of the other two fans. Lowest noise levels were typically observed for ADP Fan1 (which had a radial stator) and for the intermediate tip speed fan (Source Diagnostics Test, SDT, R4 rotor) with a swept stator. Projected noise levels for the ADP fan to the SDT swept stator configuration at design point conditions showed the fans to have similar noise levels. However, it is possible that the ADP fan could be 2 to $3 \mathrm{~dB}$ quieter with incorporation of a swept stator. Benefits of a scaled ADP fan include avoidance of multiple pure tones associated with transonic and higher blade tip speeds. Penalties of a larger size ADP fan would include increased nacelle size and drag.
\end{abstract}

\section{Introduction}

$\mathrm{T}$ HERE is a continuing effort to reduce modern turbofan engine noise to allow aircraft to satisfy increasingly stringent airport noise regulations. Significant engine noise reductions have been achieved utilizing higher bypass ratios/lower jet velocities, advanced rotor/stator designs which minimize wake interactions, rotor design changes which reduce transonic rotor multiple pure tones, etc. There continues to be uncertainty as to the relative acoustic benefits of "tradeoffs" between these parameters. Higher pressure ratios (PR) which are usually associated with higher design tip speed and blade loading can result in a reduced engine diameter (reduced nacelle drag and possibly engine weight). However, higher tip speeds (transonic and above) introduce shaft order multiple pure tones (MPTs) which can adversely affect the engine's noise rating. Lower tip speed/lower stage pressure ratio designs can operate below transonic rotor tip speed thereby avoiding MPT noise generation. However, these lower tip speed designs usually mandate the use of a reduction gearbox between the high speed core turbine and lower speed bypass fan. This gearbox may introduce additional complexity and weight into the turbofan engine. Additionally, the reduced stage PR of these designs will result in a somewhat larger diameter engine to achieve the same thrust as that of a higher tip speed/stage PR design.

Model turbofan far-field acoustic tests, such as those performed in the NASA Glenn Research Center 9- by 15Foot Low Speed Wind Tunnel $(9 \times 15$ LSWT) have provided valuable data for advanced model bypass fan stages. Fans tested in the $9 \times 15$ LSWT are all designed to a common 22-in. rotor tip diameter. These test results are valuable for documenting noise benefits associated with changes in blade/stator design, bypass nozzle area, incorporation of acoustic liners, etc.

Fan noise levels are best compared on a fan stage thrust basis, since stage thrust is the ultimate metric of significance when selecting an aircraft engine design. Such noise comparisons between fan designs are easily performed when test acoustic data exists for similar stage thrust levels. Noise comparisons become much more tenuous when it is necessary to project noise levels taken for a lower PR/thrust fan stage for comparison to those for

*Aerospace Engineer, NASA Glenn Acoustics Branch, 21000 Brookpark Road, and Senior Member. 
a higher PR/thrust design at equivalent rating fan speeds (approach, cutback, takeoff). This report will compare farfield noise results for three significantly different model turbofans which were tested in the $9 \times 15$ LSWT in an effort to compare relative noise generation mechanisms for these fans and to evaluate methodology for estimating noise level changes associated with geometrically increasing the fan size to achieve desired stage thrust levels.

\section{Test Description}

\section{A. 9×15 Wind Tunnel Facility}

The $9 \times 15$ LSWT test section walls, floor, and ceiling have acoustic treatment to produce an anechoic test environment. ${ }^{1-3}$ Sideline acoustic data were acquired with a computer-controlled translating microphone probe and with three aft microphone assemblies mounted to the tunnel floor. The translating microphone probe acquired data at 48 sideline geometric angles from $27.2^{\circ}$ to $134.6^{\circ}$ relative to the fan rotor plane. The probe traverse was 89 in. from the fan rotational axis (about four fan diameters). The three fixed microphone assemblies were mounted at the same axial distance as the downstream traverse position to acquire aft acoustic data at geometric angles of $140^{\circ}, 150^{\circ}$, and $160^{\circ}$. Figure 1 is a sketch of a typical model turbofan installed in the $9 \times 15$ LSWT anechoic test section. Fan acoustic data were acquired at $0.10 \mathrm{M}$ tunnel flow to achieve acoustic flight effect. ${ }^{4}$ The far-field data were instrument corrected (adjusted for microphone, cable, and streamlined bullet nose response) and adjusted for atmospheric attenuation. The far-field data are presented as lossless results on the 89 in. sideline at emission angles relative to the model fan rotor plane $\left(25^{\circ}\right.$ through $\left.158^{\circ}\right)$. The acoustic data were acquired through a digital computer system and stored for post-run analysis.

\section{B. Model Turbofans}

This paper compares far-field acoustic results for three model turbofans which were tested in the NASA Glenn 9- by 15-Foot Low Speed Wind Tunnel. All of the fan results are for the hardwall configuration without acoustic treatment. Table 1 compares selected design parameters for these three model fans. The fan design conditions represent a significant value range. The Advanced Ducted Propulsor (ADP) Fan1 had a subsonic design tip speed $(840 \mathrm{ft} / \mathrm{s})$ in contrast to the supersonic design tip speeds for the Source Diagnostic Test (SDT) and Quiet High Speed Fan2 (QHSF2) stages. Thus, the ADP Fan1 never reached transonic or higher rotor speeds which typically generate shaft order multiple pure tones (MPTs) in the acoustic spectra. The design bypass pressure ratio also increased with tip speed from a low of 1.29 for the ADP fan to a high of 1.82 for the QHSF. The design corrected inlet weight flows were similar for the three fans, although the lower flow for the ADP fan is somewhat due to the higher rotor hub/tip ratio and consequent reduced flow area for that fan.

There has been a question as to whether a core flow should be modeled in a research fan stage. The presence of a core flow more accurately represents the aerodynamics of the fan stage in an engine installation. However, an active core (with a core rotor) introduces additional noise sources which would likely be absorbed by an actual engine's downstream turbine/combustor, but which radiate freely to the far-field in a research model fan. Thus the ADP and QHSF offer a compromise solution with a passive core flow (no core rotor) which should have no significant acoustic contribution to the far field noise - especially potential core noise due to blade/vane interaction. The SDT fan followed the alternate philosophy of simply not including a core flow.

Bypass blade/vane numbers have typically been selected to cut-off propagation of the fundamental interaction tone, ${ }^{5}$ satisfying the cut-off criterion results in the vane number being somewhat greater than twice the rotor number. These three model fans satisfy the cut-off criterion, except for the SDT with the swept stator. Increased rotor-stator axial spacing will also reduce the severity of the rotor wake interaction with the stator and consequent tone generation. Incorporating stator sweep has been shown to effectively reduce rotor/stator tone generation. ${ }^{6}$

The ADP Fan1 (Fig. 2) has a relatively low stage pressure ratio (1.29) and a subsonic design tip speed. ${ }^{6,7}$ Fan1 has a radial bypass stator and a passive core with a 63-vane stator (Fig. 3). This fan has the highest design bypass ratio (13.3) of the three fans considered in this paper. The subsonic design tip speed of this fan avoids the generation of multiple pure tones. However, the stage thrust for this 22-in. diameter fan was significantly lower than that of the other two fans in this study, such that Fan1 would require a significant size increase to generate the thrust levels observed for the SDT and QHSF stages.

Figure 4 shows a photograph of the model SDT fan installed in the NASA Glenn $9 \times 15$ LSWT. $^{8,9}$ This test series investigated two rotor and three stator configurations, as well as a unique rotor-alone configuration in which the nacelle was externally supported and aligned with the rotor. SDT results presented herein are for the R4 rotor and baseline 52 vane radial stator, and for the "quietest" configuration with the R4 rotor and a 26-vane swept stator. Cross-sectional sketches are also shown in Fig. 4 for the two representative SDT configurations. The SDT fan had a 
design corrected tip speed of $1215 \mathrm{ft} / \mathrm{s}$ and a stage pressure ratio of 1.47 . The higher vane count baseline stator satisfies the cut-off criterion of reference 5, although the cut-on swept stator provided a greater overall noise reduction.

Figure 5 is a photograph of the QHSF Fan2 model installed in the $9 \times 15$ LSWT. ${ }^{10,11}$ This fan model has the highest design tip speed $(1474 \mathrm{ft} / \mathrm{s})$ of the three model fans in this study. The QHSF has a swept, cut-off bypass stator, although the bypass rotor-stator spacing fairly close for this fan stage (Fig. 6). This fan also has a passive core flow with 10 support struts (effectively stator vanes). The bypass ratio (3.8) is well below that of the other two model fans.

\section{Results and Discussion}

The scope of this analysis is to compare acoustic performance of these fans at similar stage thrust levels. This comparison will provide insight to the relative noise generation mechanisms (blade/vane interaction tones, broadband, multiple pure tones, etc.) that dominate the respective fan acoustic performance for a particular stage thrust. Additionally, a thrust-based noise correction will be used for the ADP Fan1 to predict the likely noise characteristics of a scaled-up version of that fan.

There are a number of noise "trade-offs" between these three fans. Increased rotor/stator axial spacing is desirable to allow dissipation of the rotor wake and resulting wake interaction with the stator. The ADP and SDT fans employ a large rotor/stator spacing (on the order of 3 rotor chords), however the QHSF rotor/stator spacing is significantly less. Stator sweep has also been recognized as a significant noise reduction mechanism, and is employed on one of the SDT configurations as well as the QHSF (but not for the ADP fan). The QHSF also has the potential for tone noise generation due to the presence of robust downstream support struts. All of these fans were tested with hardwall flow ducts, although it is recognized that properly designed acoustic liners can further reduce fan noise levels

Figure 7 compares the overall sound power level for these fans as a function of corrected stage thrust. As previously mentioned, the ADP Fan1 stage produced significantly less thrust than did the other two model fans. Thus, it would be necessary to scale Fan1 (while maintaining rotor tip speed) to a larger diameter to achieve higher thrust levels. However, with a subsonic design rotor tip speed, Fan1 would not incur multiple pure tones at cutback and takeoff fan speeds. The onset of MPTs is clearly evident in Fig. 7 for the SDT and QHSF stages. The SDT fan shows an abrupt increase in noise near a thrust level of $1800 \mathrm{lb}$, which corresponds to a rotor tangential tip speed of about $1100 \mathrm{ft} / \mathrm{s}$. The MPT - induced noise increase for the QHSF2 occurs at a somewhat lower stage thrust (about $1550 \mathrm{lb}$ ) where the tangential tip speed for that fan is likewise near $1100 \mathrm{ft} / \mathrm{s}$. Comparison points of essentially equivalent stage thrust (designated "A" through "H", Table 2) shown on Fig. 7 will be used for the following far field noise comparisons in Figs. 8 through 15. Results are shown for lossless sound power level (PWL) spectra and overall sound pressure level (OASPL) integrated from $1 \mathrm{k}$ to $50 \mathrm{kHz}$. Sound power level spectra were calculated from the SPL spectra assuming spherical symmetry through the range of sideline data acquisition. Possible noise contributions outside the sideline range were ignored.

Comparison Point "A" is for a nominal stage thrust of $540 \mathrm{lbf}$. (Fig. 8). The QHSF2 is clearly noisier at this relatively low thrust, having both strong interaction tone levels (especially 3 and 4BPF) as well as higher broadband noise levels. The significance of this higher broadband level for the QHSF is evident in the OASPL directivities of Fig. 8 where the QHSF dominates - especially in the forward quadrant.

Comparison Point "B" (Fig. 9) shows relative noise levels for two configurations of the SDT fan and the ADP Fan1. Rotor/stator interaction tone levels are stronger for the ADP fan (which is cut-off with respect to propagation of the fundamental BPF tone. Although typically the quietest configuration, the SDT with the cut-on swept stator does show a significant BPF tone level. Interaction tone levels for the SDT fan with the cut-off baseline stator are negligible. Broadband noise levels for the SDT with swept stator and ADP fans are essentially the same at this thrust level. Directivity results for the two SDT stator configurations and the ADP fan show that the ADP fan is quietest in the forward quadrant, but not in the aft quadrant where the SDT R4+swept stator configuration shows the lowest noise levels.

Comparison Point "C" (Fig. 10) shows the QHSF2 to have both the highest interaction tone and broadband noise levels (with the possible exception of the fundamental tone level for the cut-on SDT with the swept stator). The SDT with the swept stator configuration consistently shows lower broadband noise levels (especially at lower fan speeds).

Relative noise levels for all three subject fans were possible at Comparison Point "D" (Fig. 11). Rotor tip speed for all three fans remains subsonic (although the QHSF2 at $1050 \mathrm{ft} / \mathrm{s}$ is close to transonic). There are many "tradeoffs" in the PWL spectra for these fans. The SDT with swept stator typically shows the lowest broadband noise levels. The QHSF2 shows a number of significant interaction tone orders (2BPF and higher), although the 2BPF 
interaction tone for the ADP is likewise significant. Interaction tones for the SDT with the swept stator are insignificant. The OASPL directivities for all of these fans are aft-dominated; the highest noise levels are associated with the ADP fan. This is in contrast to the forward quadrant where the ADP fan is quietest and the other three fan noise levels (QHSF and SDT with two stator configurations) are essentially the same.

Noise levels at Comparison Point "E" contrast noise levels for the QHSF2 with a supersonic rotor tip speed $(1200 \mathrm{ft} / \mathrm{s})$ with the SDT at a high subsonic (1033 ft/s) rotor tip speed (Fig. 12). ADP data are thrust-limited and therefore not available at this and higher comparison points. Tone levels for the QHSF strongly dominate the PWL spectra, including a very strong cut-on BPF tone. Broadband noise levels for the QHSF and SDT with the baseline stator are essentially the same, while the broadband noise levels for the SDT with the swept stator are about $2 \mathrm{~dB}$ lower. The OASPL directivity plots in Fig. 12 show the strong QHSF tone contributions - especially in the forward quadrant.

Both the QHSF2 and SDT fan tip speeds are transonic or higher at Comparison Point "F" (Fig. 13), thus there are strong rotor tones (including BPF) for both fans. Broadband noise levels are consistently highest for the QHSF. The swept stator SDT configuration continues to show some reduction in broadband noise level relative to that for the baseline stator SDT configuration. The OASPL directivities at this comparison point clearly show the higher noise levels associated with the QHSF. Directivities for the SDT configurations show a modest benefit associated with the swept stator toward the aft quadrant.

At Comparison Point "G" (Fig. 14) the two fans are operating at a supersonic tip speed. Tone levels continue to dominate the PWL spectra for the QHSF2 and both SDT configurations. The QHSF has the highest broadband levels, although only slightly higher than SDT broadband levels with the baseline stator. The swept stator SDT configuration continues to show lower broadband levels. It is interesting to note that while the presence of multiple pure tones is clearly evident in the SDT spectra, it is possible that the higher broadband noise levels associated with the QHSF essentially masks the presence of MPTs for that fan.

The last noise comparison, Comparison Point "H" (Fig. 15) compares the QHSF2 and SDT operating at a supersonic rotor tip speed. The PWL spectra is highest both in terms of rotor tones and broadband noise level for the QHSF. There are both tone and broadband noise benefits associated with the swept stator relative to the baseline radial stator for the SDT fan.

Figures 8 through 15 have shown noise comparisons for three significantly different fans at similar stage thrust levels. These fans have the same rotor tip diameter, but differ in design stage pressure ratio, rotor tip speed, and blade/vane geometry. The high design tip speed QHSF Fan2 was shown to have the highest noise levels both for rotor tones (rotor wake interaction and rotor-alone) and broadband noise. The QHSF does feature a swept bypass stator, which has been associated with lower fan noise levels; however the rotor/stator spacing for this fan is significantly less than that for the other fans in this study. Additionally, the QHSF has downstream support struts which could also contribute to tone noise levels.

The low-speed, low stage pressure ratio ADP Fan1 and the intermediate speed/pressure ratio SDT fan incorporating a swept bypass stator had similar noise levels. While the ADP fan had a significant rotor/stator axial spacing, it did have a radial, rather than swept, stator. Acoustic tests of the SDT and other fans tested in the $9 \times 15$ LSWT $^{12}$ have documented an acoustic benefit on the order of $2 \mathrm{~dB}$ to $3 \mathrm{~dB}$ associated with sweeping the bypass stator. Thus it is possible that noise levels for the ADP stage could be somewhat reduced by replacing the radial bypass stator with a swept design.

It is acceptable to adjust noise levels for a geometrically-scaled fan according to $10 \log$ (thrust ratio) ${ }^{13}$ Figures 16 and 17 show how the spectra for a scaled-up version of the ADP Fan1 might compare with the two SDT configurations at design fan speed. This noise adjustment for the ADP fan was made using the thrust ratio at design fan speed for the ADP and SDT fans. A scaled-up version of the ADP fan would still preserve its design $840 \mathrm{ft} / \mathrm{s}$ subsonic tip speed. Figure 16 shows how the PWL spectra for the scaled ADP Fan1 might compare with the SDT fan with the lower-noise swept stator. Tone noise for the scaled ADP fan is somewhat stronger than those for the SDT fan. Broadband noise levels for the two fans are essentially the same. However, the SDT fan, operating at a supersonic rotor tip speed, has a MPT contribution which is not seen for the ADP fan. Overall, it would appear that the noise levels for the scaled ADP fan and for the SDT fan with the swept stator are about equivalent. As previously mentioned, the ADP fan has a radial bypass stator. It is possible that noise levels for the ADP fan might be reduced by 2 or more $\mathrm{dB}$ by incorporating a swept bypass stator design. Figure 17 compares the PWL spectra for the scaled ADP fan with that for the SDT fan with the radial baseline stator at design fan speed. As expected, noise levels for this configuration of the SDT fan show significantly higher broadband levels as well as slightly higher tone levels. 
Scaling fan noise according to $10 \log$ (thrust ratio) is only valid for a geometrically-scaled fan. Otherwise, it is necessary to establish a noise/thrust correlation for a particular fan and apply that correlation to estimate noise changes with fan speed, etc. Figure 18 shows how such a correlation might be applied to the ADP Fan1 plot of OAPWL versus stage thrust. In this case, a noise adjustment of 24.1 log (thrust change) is indicated. Such a curve fit has limited extrapolation validity since fundamental changes in the fan noise characteristics due to factors such as transonic rotor tip speed, etc. may apply. Also, the coefficient of this thrust based adjustment is specific to a particular fan stage.

\section{Concluding Remarks}

Far-field noise sound power level (PWL) spectra and overall sound pressure level (OASPL) directivities were compared for three significantly different model fan stages which were tested in the NASA Glenn $9 \times 15$ Low Speed Wind Tunnel. These fans had design rotor tip speeds from 840 to $1474 \mathrm{ft} / \mathrm{s}$ and stage pressure ratios from 1.29 to 1.82. A lower design tip speed avoids generation of multiple pure tones; however the associated lower stage pressure ratio results in a lower stage thrust, thus necessitating scaling the stage diameter to achieve similar thrust levels to those for the higher tip speed/pressure ratio designs. Thrust equivalent noise levels for the high tip speed fan stage (Quiet High Speed Fan2, QHSF2) were typically highest at all comparison thrust levels. This may be due, in part by the relative close spacing of the rotor and bypass stator and presence of downstream support struts for this fan, although it did incorporate a low-noise swept bypass stator.

Noise comparisons between the low tip speed Advanced Ducted Propulsor (ADP) Fan1 and two configurations of the Source Diagnostic Test (SDT) fan showed benefits associated with both designs. The SDT fan utilizing the R4 rotor and a cut-on swept bypass stator was typically quieter than the baseline SDT configuration with the R4 rotor and a cut-off radial stator. However, fundamental rotor interaction tone reductions associated with the cut-off bypass radial stator were beneficial at lower fan speeds. The ADP Fan1 had a radial bypass stator, thus suggesting the possibility of additional noise reduction by incorporating a swept stator in this design.

The design speed ADP noise spectra was adjusted for comparison with the design speed SDT spectra according to $10 \log$ (thrust ratio), which is valid for a geometrically-scaled fan. This comparison showed that the PWL noise for the quieter SDT fan with a swept stator was essentially equivalent to that for the scaled ADP fan, although different noise mechanisms (tone level, MPTs, broadband noise) were different for the two designs. It is possible that the ADP Fan1 design would show an additional noise reduction of around $2 \mathrm{~dB}$ if a swept bypass stator were incorporated, thus making the scaled ADP the quietest fan stage. However, this lower noise for the ADP comes with the penalty of a significantly larger fan diameter (and associated drag, etc.) for the scaled fan.

\section{References}

${ }^{1}$ Dahl, M.D., and Woodward, R.P., "Comparison Between Design and Installed Acoustic Characteristics of the NASA Lewis 9-by 15-Foot Low Speed Wind Tunnel Acoustic Treatment,” NASA TP-2996, April 1990.

2Dahl, M.D., and Woodward, R.P., "Background Noise Levels Measured In the NASA Lewis 9-by 15-Foot Low Speed Wind Tunnel,” NASA TP-3274, November 1992.

${ }^{3}$ Woodward, R.P., and Dittmar, J.H., "Background Noise Levels Measured in the NASA Lewis 9- by 15-Foot Low-Speed Wind Tunnel,” NASA TM-106817, AIAA-95-0720, January 1995.

${ }^{4}$ Chestnutt, D., "Flight Effects of Fan Noise,” NASA CP-2242, January, 1982.

${ }^{5}$ Tyler, J.M., and Sofrin, T.G., “Axial Flow Compressor Noise Studies,” Society of Automotive Engineers Transactions, Vol. 70, 1962, pp. 309-322.

${ }^{6}$ Jeracki, R.J. "Comprehensive Report of Fan Performance from Duct Rake Instrumentation on 1.294 Pressure Ratio, $8.06 \mathrm{ft} / \mathrm{s}$ Tip Speed Turbofan Simulator Models,” NASA/TM-2006-213863.

${ }^{7}$ Dittmar, J.H., Elliott, D.M, and Bock, L.A., "Some Acoustic Results From the Pratt and Whitney Advanced Ducted Propulsor - Fan 1,” NASA TM-1999-209049, 1999.

${ }^{8}$ Woodward, R.P., Hughes, C.E., Jeracki, R.J., and Miller, C.J., "Fan Noise Source Diagnostic Test - Far Field Acoustic Results,” AIAA-2002-2427.

${ }^{9}$ Hughes, C.E., “Aerodynamic Performance of Scale-Model Turbofan Outlet Guide Vanes Designed for Low Noise,” AIAA2002-0374.

${ }^{10}$ Dittmar, J.H., Elliott, D.M., and Fite, E.B., “The Noise of a Forward Swept Fan,” NASA/TM-2003-212208, Nov. 2003.

${ }^{11}$ Weir, Donald, “Design and Test of Fan/Nacelle Models Quiet High-Speed Fan,” NASA/CR_2003-212370, July 2003.

${ }^{12}$ Woodward, R.P., Elliott, D.M., Hughes, C.E., and Berton, J.J., "Benefits of Swept and Leaned Stators for Fan Noise Reduction,” NASA AST018 (October 1997), NASA TM-1998-208661 (Nov. 1998), AIAA-99-0497, AIAA Journal of Aircraft, Vol. 38, Number 6, pp.1130-1138, November-December 2001.

${ }^{13}$ Dittmar, James H., “Comparison of Propeller Cruise Noise Data Taken in the NASA Lewis 8- by 6-Foot Wind Tunnel With Other Tunnel and Flight Data,” AIAA-89-1059, NASA TM-101976, April, 1989. 
Table 1. Model Fan Stage Design Parameters-Hardwall Flow Ducts

\begin{tabular}{|c|c|c|c|}
\hline Parameter & ADP Fan1 & SDT (R4 rotor) & QHSF2 Baseline Fan \\
\hline Corrected tip speed (ft/s) & 840 & 1215 & 1474 \\
\hline Stage pressure ratio & 1.29 & 1.47 & 1.82 \\
\hline Rotor hub/tip ratio & 0.43 & 0.30 & 0.35 \\
\hline $\begin{array}{l}\text { Corrected weight flow } \\
\left(\mathrm{lbm} . / \mathrm{ft}^{2}-\mathrm{s}\right)\end{array}$ & 36.9 & 41.8 & 43.7 \\
\hline $\begin{array}{l}\text { Inlet corrected weight flow } \\
(\mathrm{lbm} / \mathrm{s})\end{array}$ & 85.7 & 100.5 & 98.9 \\
\hline Bypass rotor number & 18 & 22 & 22 \\
\hline Bypass stator number & 45 & $\begin{array}{c}54 \text { - baseline radial } \\
26-\text { swept }\end{array}$ & 52 \\
\hline Bypass ratio & 13.3 & 8.9 & 3.8 \\
\hline Core & Passive - 63 vanes & None & Passive -10 struts \\
\hline $\begin{array}{l}\text { Bypass support struts } \\
\text { (downstream of stator) }\end{array}$ & None & None & 10 \\
\hline
\end{tabular}

Table 2. Model Fan Stage Comparison Points

(Reference to Fig. 7)

\begin{tabular}{|c|c|c|c|c|c|c|}
\hline \multirow{2}{*}{$\begin{array}{c}\text { Comparison } \\
\text { point }\end{array}$} & \multicolumn{3}{|c|}{ Corrected rotor tip speed, ft/s } & \multicolumn{3}{c|}{ Corrected stage thrust, lbf. } \\
\cline { 2 - 7 } & ADP Fan1 & SDT & QHSF2 & ADP Fan1 & SDT & QHSF2 \\
\hline A & 566 & N.A. & 750 & 544 & N.A. & 538 \\
\hline B & 643 & 750 & N.A. & 730 & 772 & N.A. \\
\hline C & N.A. & 790 & 945 & N.A. & 881 & 925 \\
\hline D & 801 & 911 & 1050 & 1191 & 1223 & 1172 \\
\hline E & N.A. & 1033 & 1200 & N.A. & 1639 & 1612 \\
\hline F & N.A. & 1094 & 1275 & N.A. & 1829 & 1851 \\
\hline G & N.A. & 1154 & 1350 & N.A. & 2138 & 2119 \\
\hline H & N.A. & 1215 & 1404 & N.A. & 2417 & 2341 \\
\hline
\end{tabular}

SDT values shown for swept stator; SDT not included in Point A comparison. 


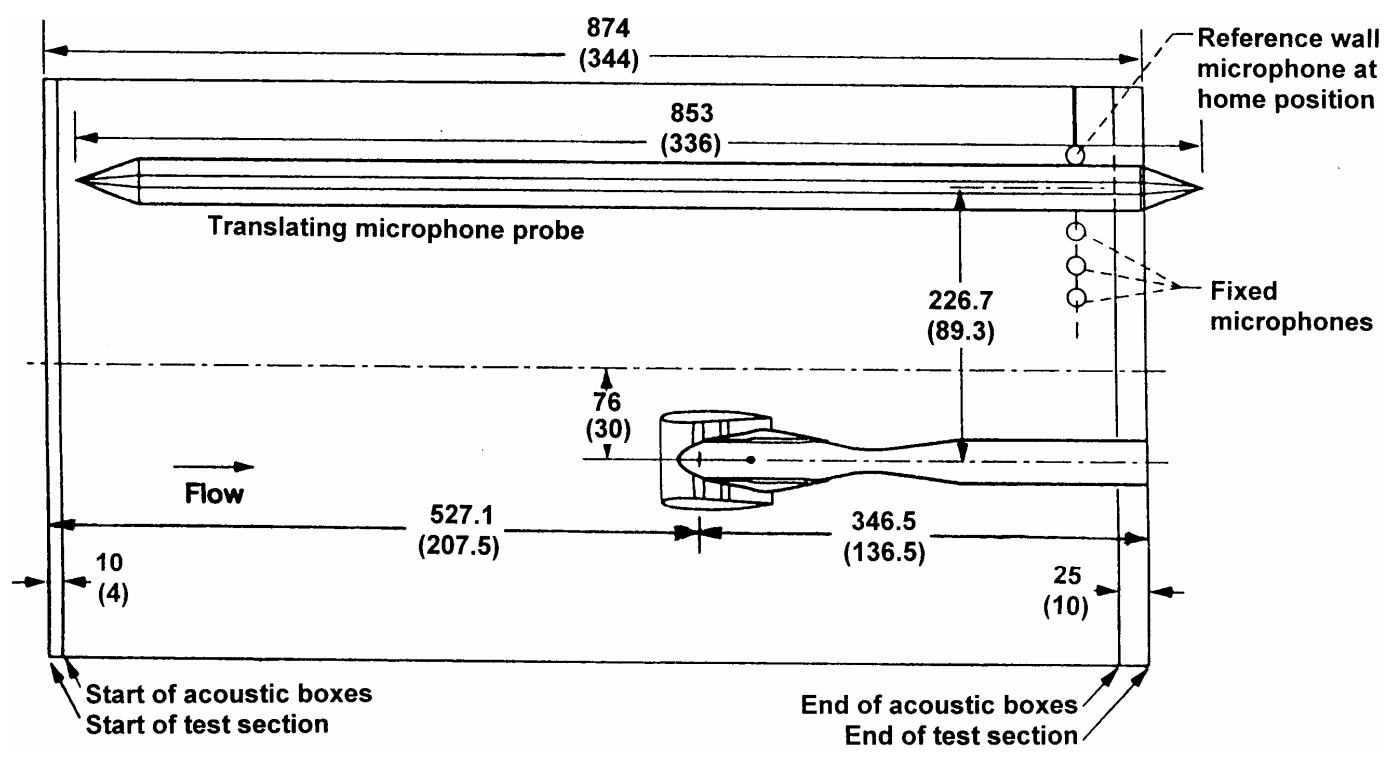

Figure 1. Sketch of the model fan installed in the 9- by 15-Foot Low Speed Wind Tunnel. Far-field acoustic data were acquired with a translating microphone probe and aft fixed microphones. (Dimensions in cm (in.)).

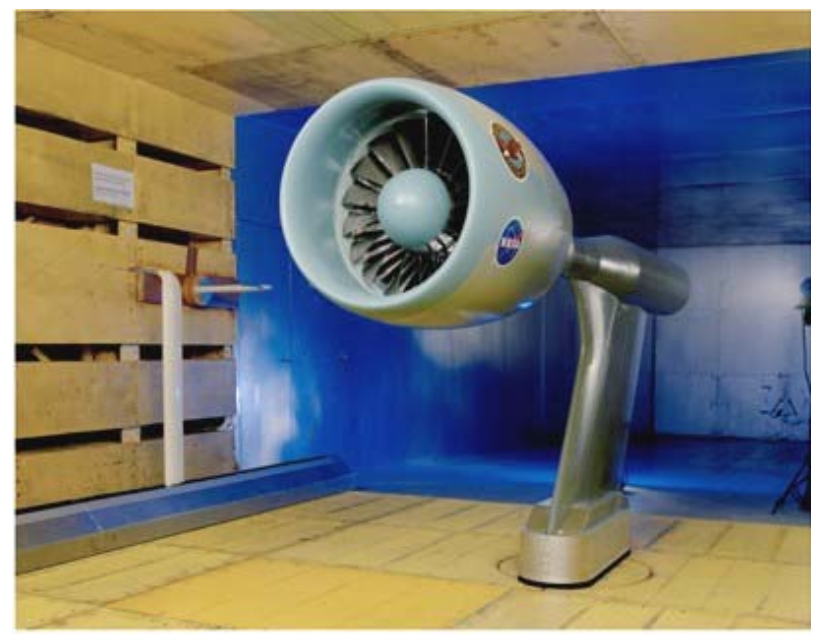

Figure 2. Photograph of Advanced Ducted Propulsor (ADP) Fan1 installed in the $9 \times 15$ LSWT.

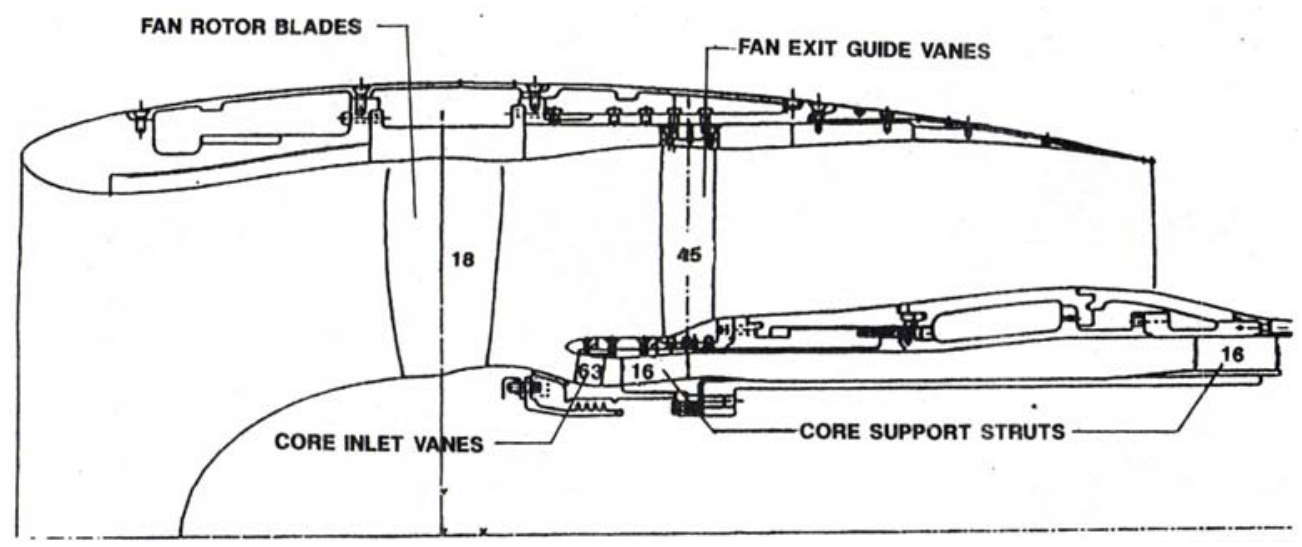

Figure 3. Sketch of the ADP Fan1 Model Turbofan. 

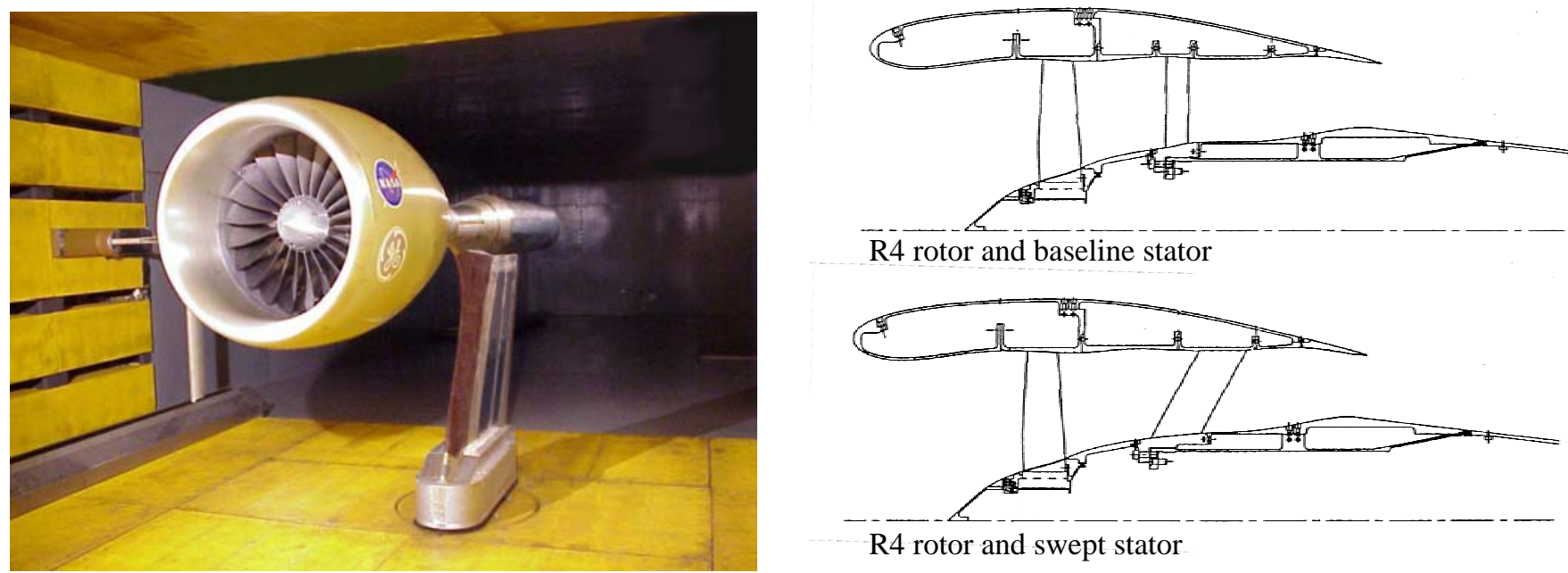

$\mathrm{R} 4$ rotor and baseline stator

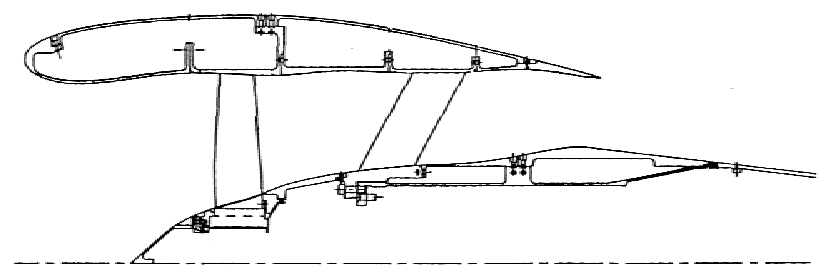

$\mathrm{R} 4$ rotor and swept stator

Figure 4. Source Diagnostic Test (SDT) model fan installed in the 9×15 LSWT. Cross-sectional sketches show the fan stage with the baseline $\mathrm{R} 4$ rotor and two stators.

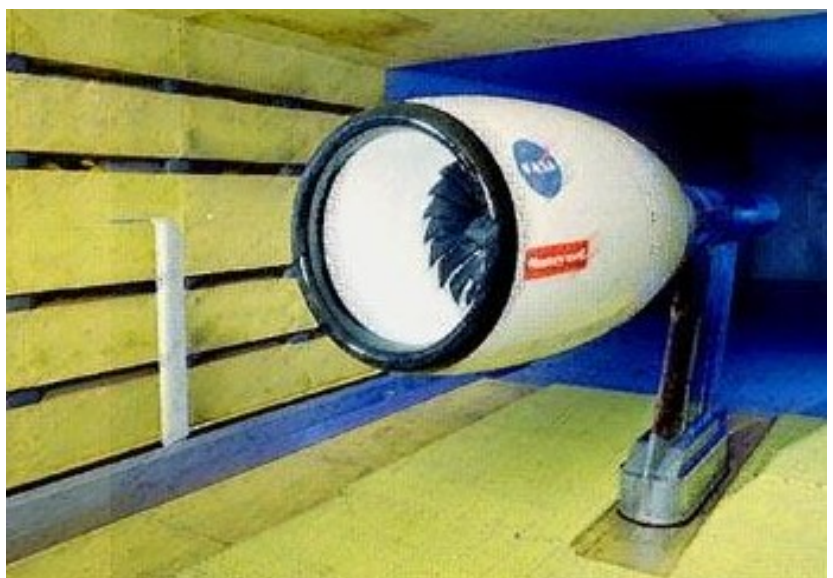

Figure 5. Photograph of the Quiet High Speed Fan 2 (QHSF2) installed in the $9 \times 15$ LSWT.

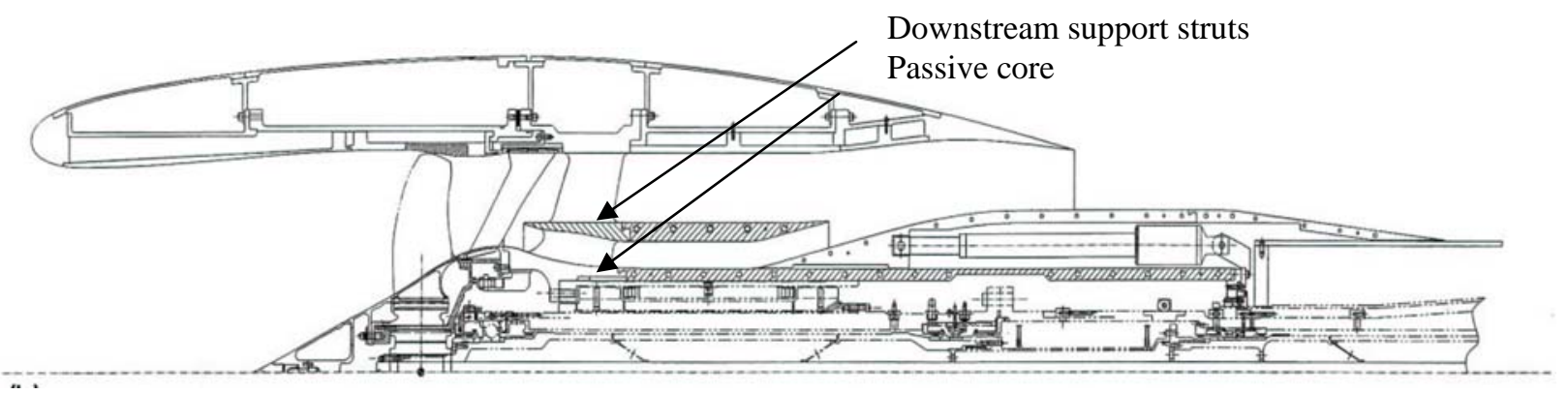

Figure 6. Cross-sectional sketch of the QHSF2 model turbofan with the baseline rotor and swept stator. Twelve downstream support struts extended into the passive core passage. 


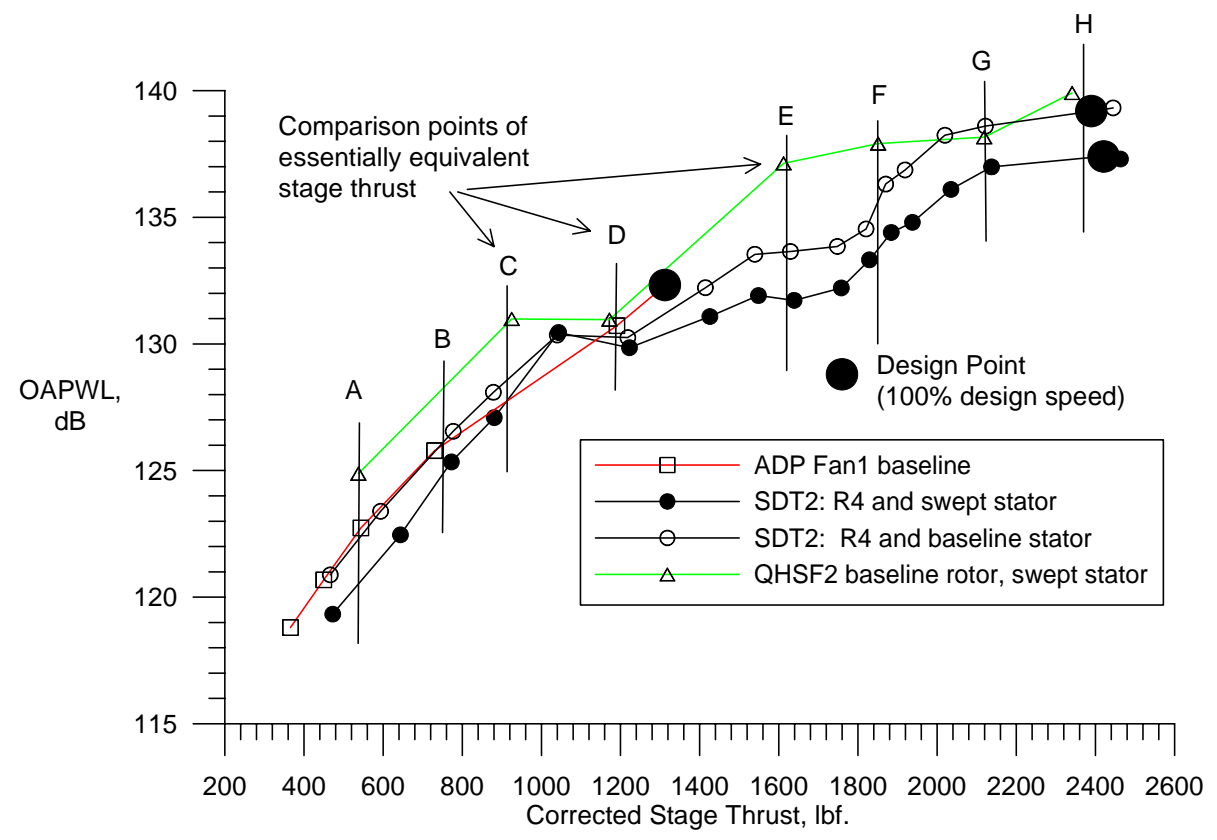

Figure 7. Comparison of OAPWL as a function of measured stage thrust for the three model fans showing possible comparison points. (Lossless OAPWL calculated from $1 \mathrm{k}$ to $50 \mathrm{kHz}$, fan design points shown for ADP and SDT; QHSF2 data were only taken up to $\mathbf{9 3 . 6}$ percent design fan speed).

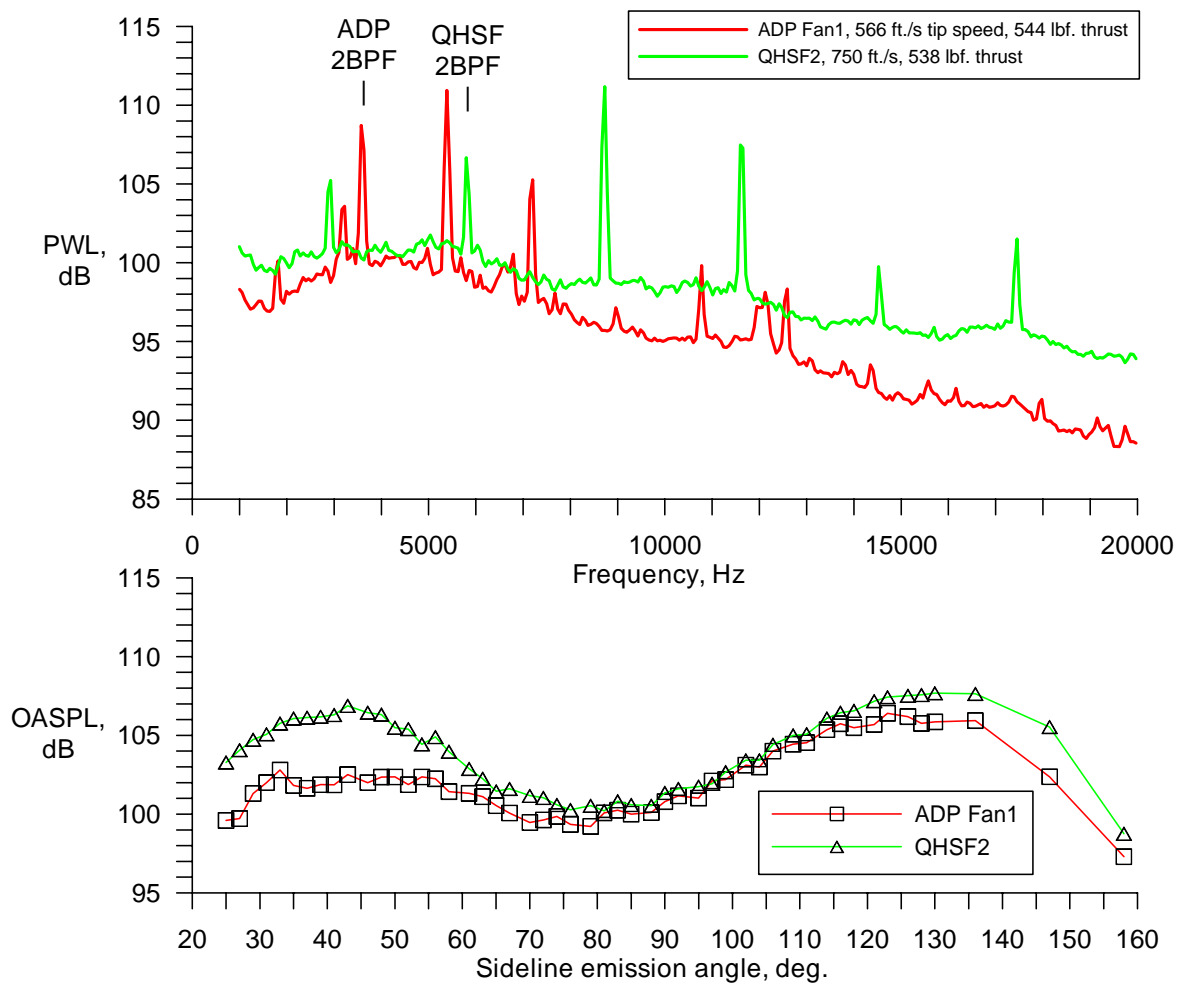

Figure 8. Far field noise comparison at "Point A" (OASPL integrated from 1 k to $50 \mathrm{kHz})$.

American Institute of Aeronautics and Astronautics 

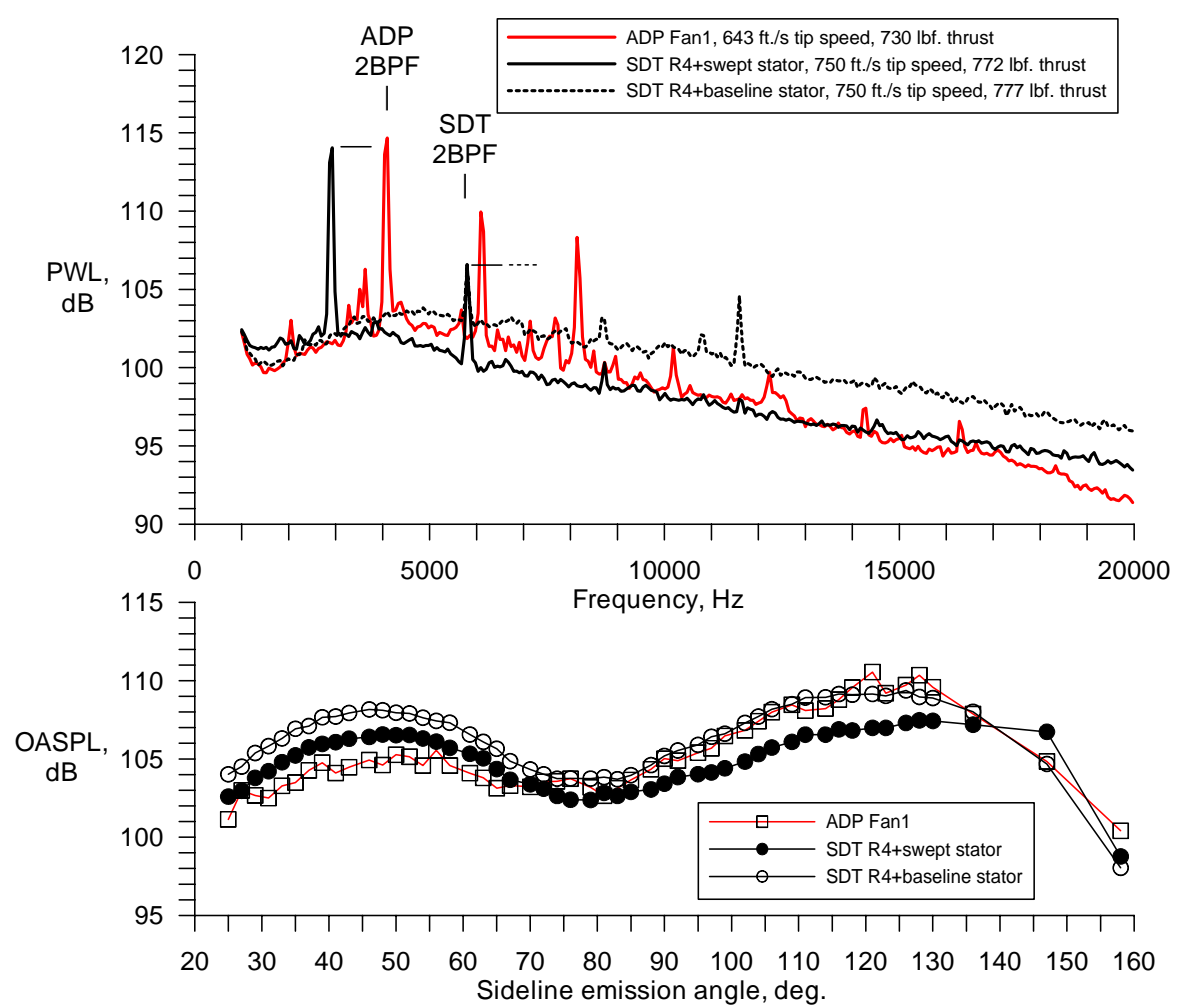

Figure 9. Far field noise comparison at "Point B" (OASPL integrated from 1 k to $50 \mathrm{kHz}$ ).

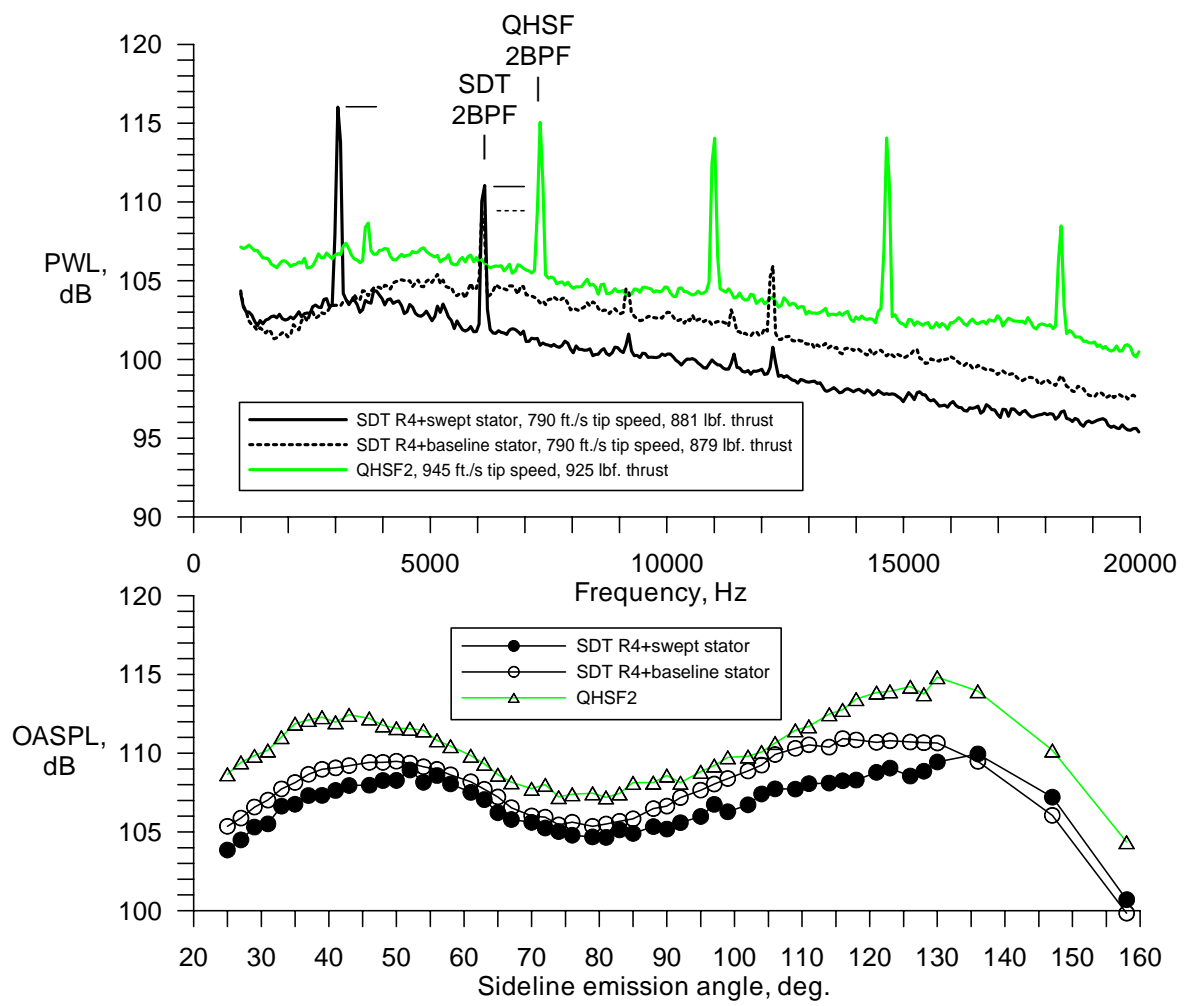

Figure 10. Far field noise comparison at "Point C" (OASPL integrated from $1 \mathrm{k}$ to $50 \mathrm{kHz})$. 

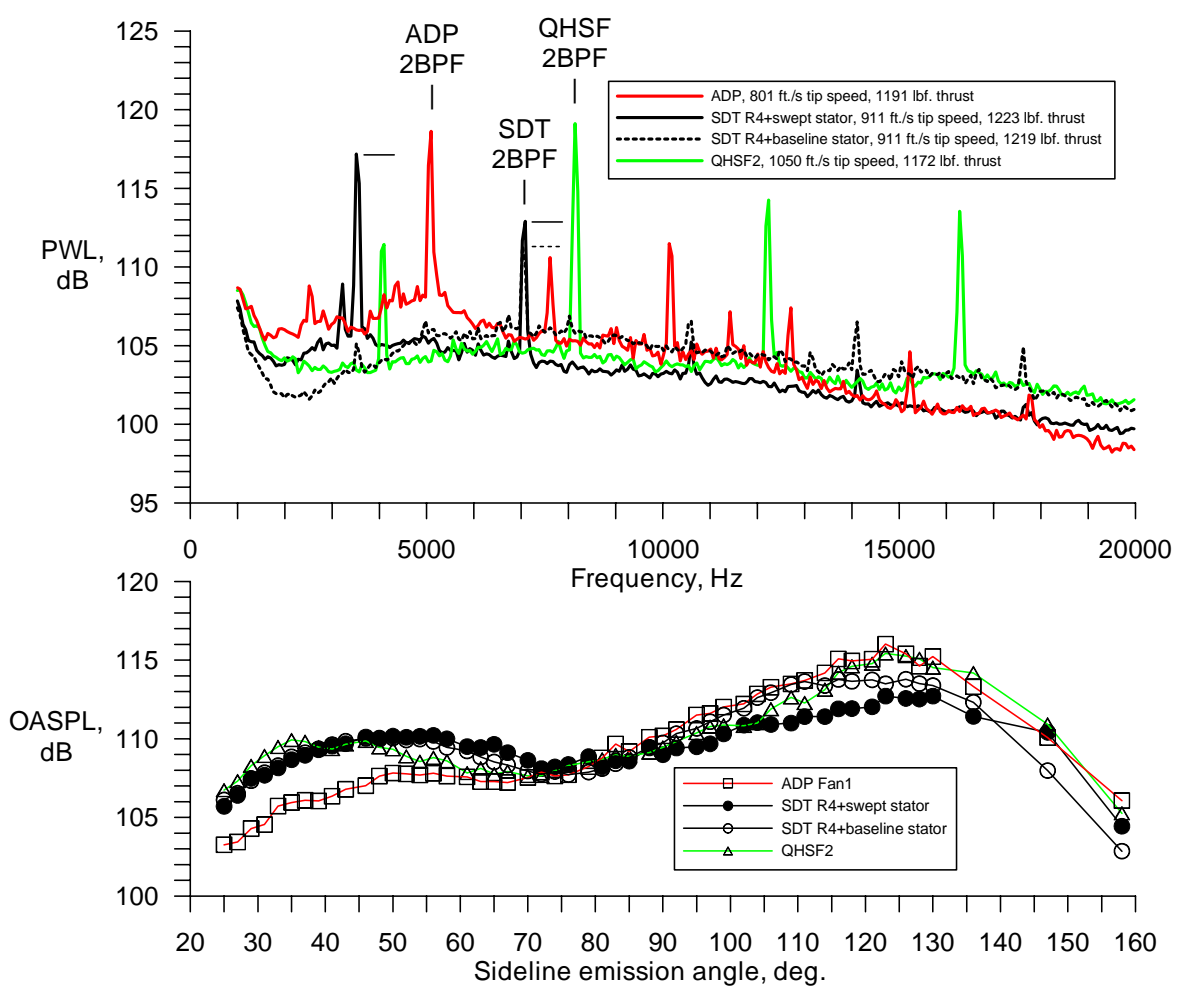

Figure 11. Far field noise comparison at "Point D" (OASPL integrated from 1 k to $50 \mathrm{kHz})$.

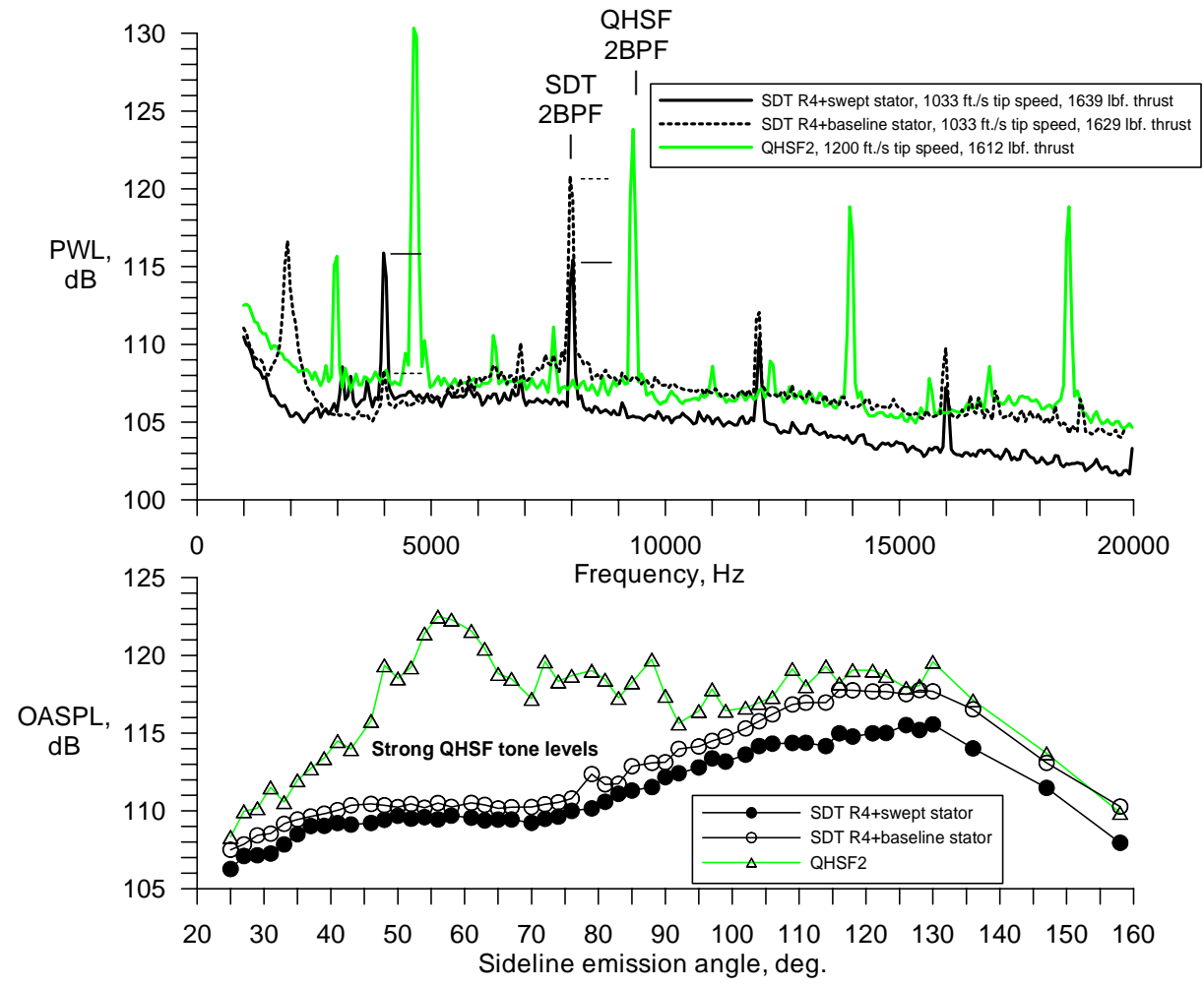

Figure 12. Far field noise comparison at "Point E" (OASPL integrated from $1 \mathrm{k}$ to $50 \mathrm{kHz}$ ). 


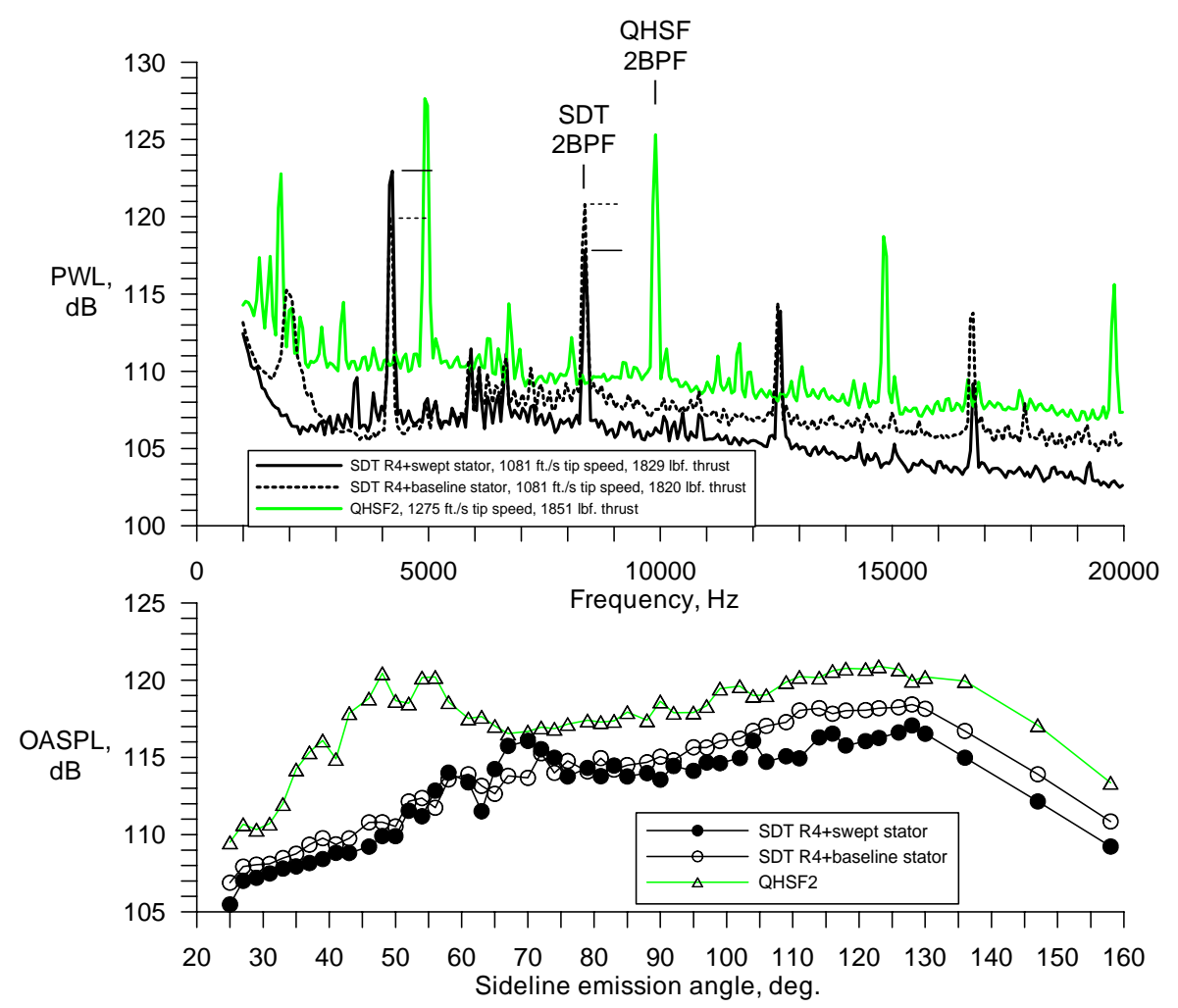

Figure 13. Far field noise comparison at "Point F" (OASPL integrated from 1 k to $50 \mathrm{kHz}$ ).

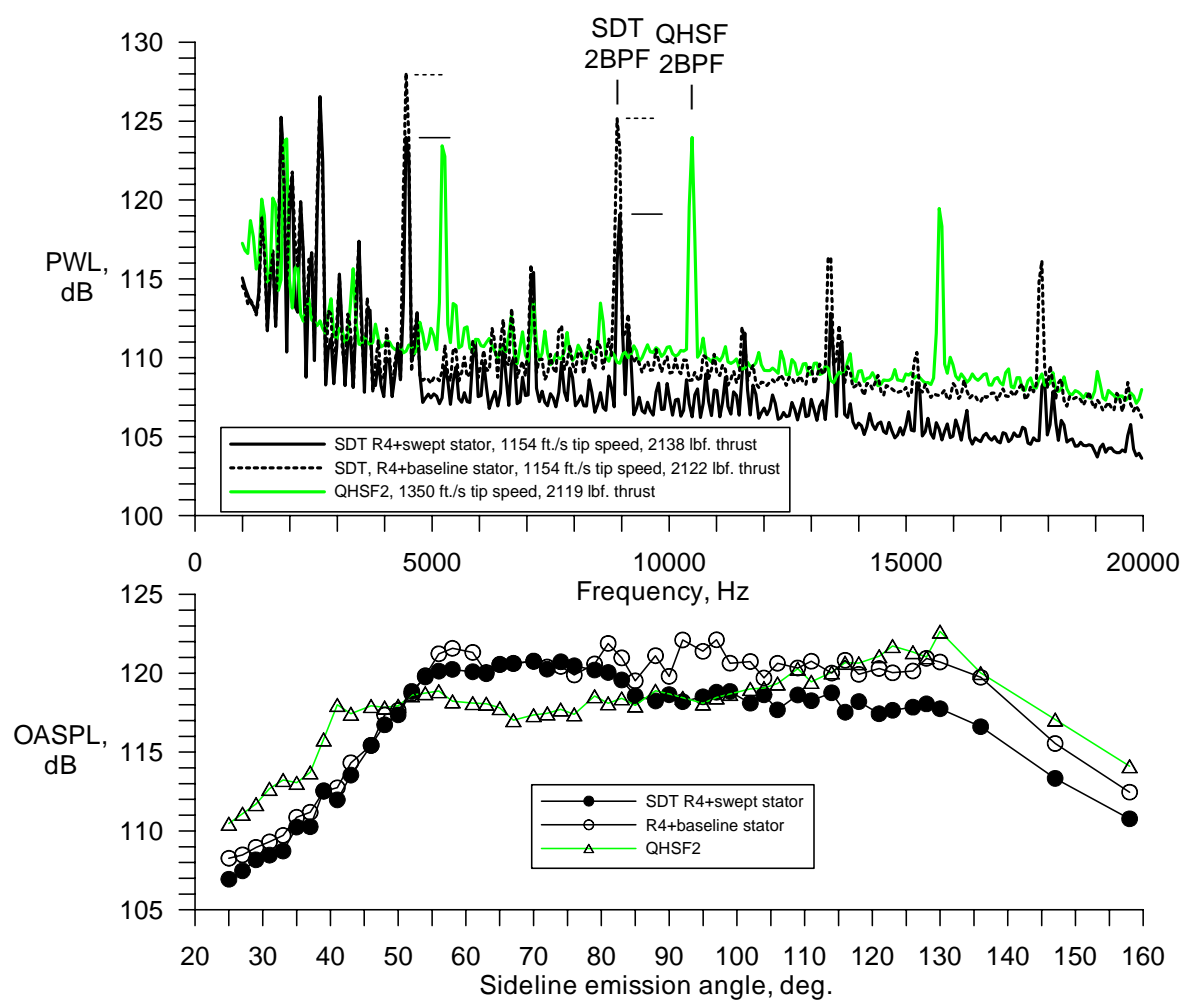

Figure 14. Far field noise comparison at "Point G" (OASPL integrated from 1 k to $50 \mathrm{kHz}$ ). 


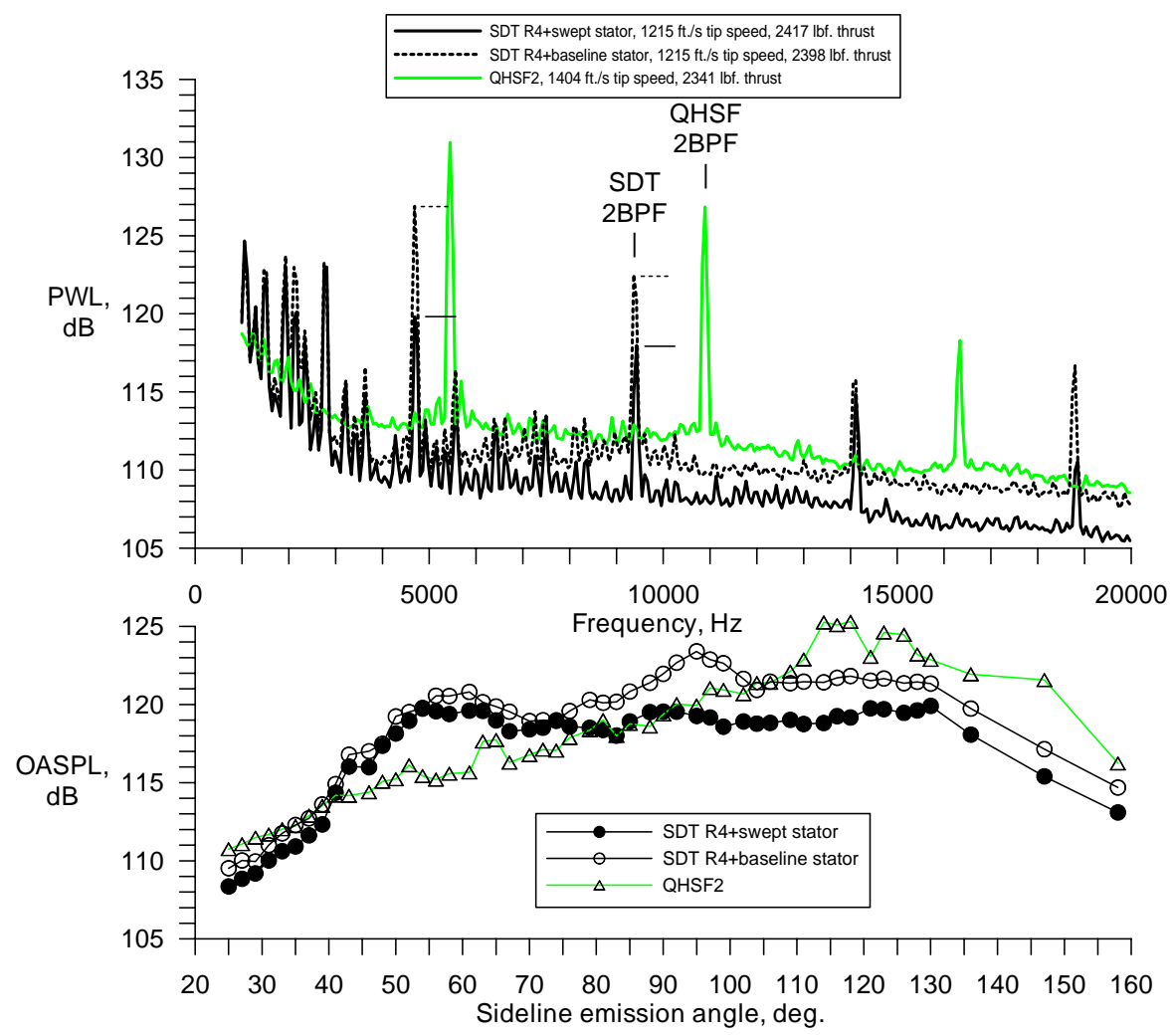

Figure 15. Far field noise comparison at "Point $H$ " (OASPL integrated from $1 \mathrm{k}$ to $50 \mathrm{kHz})$.

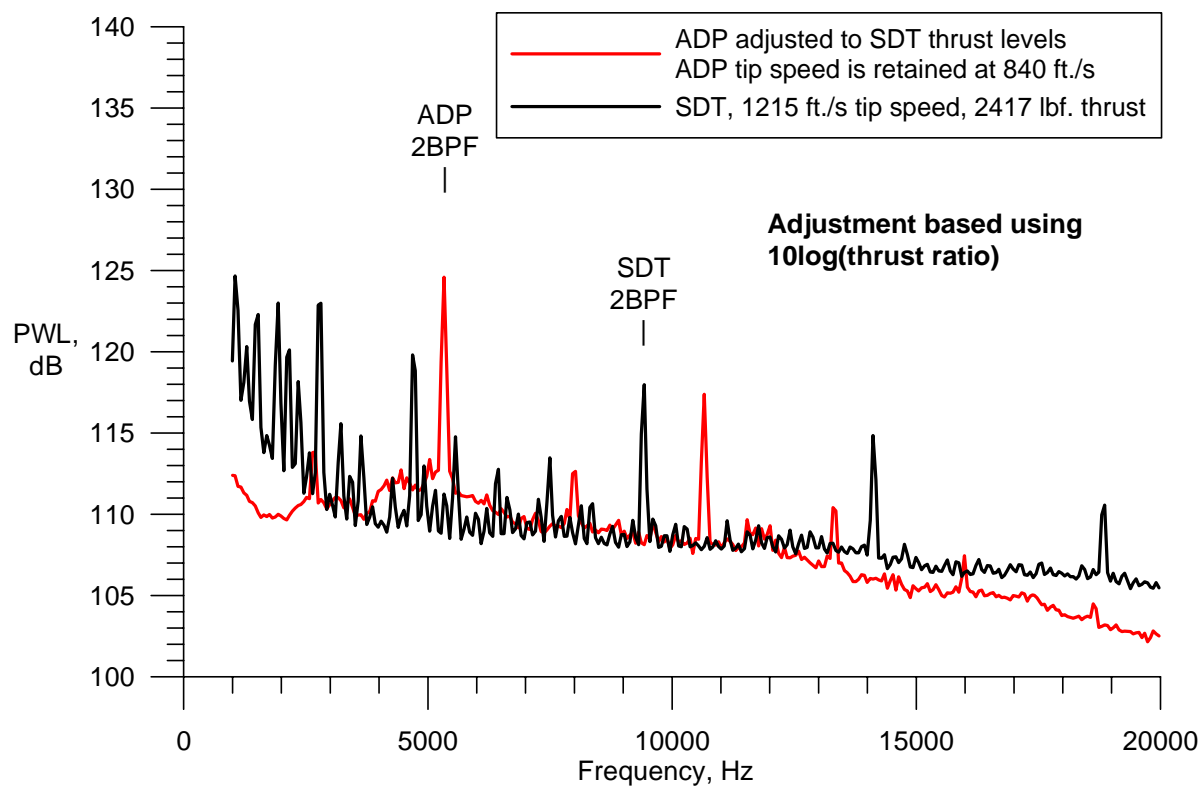

Figure 16. PWL spectra comparison of SDT (R4+swept stator) at design speed, and ADP Fan1 using 10log (thrust ratio) to adjust ADP (design fan speed) noise to SDT thrust level. 


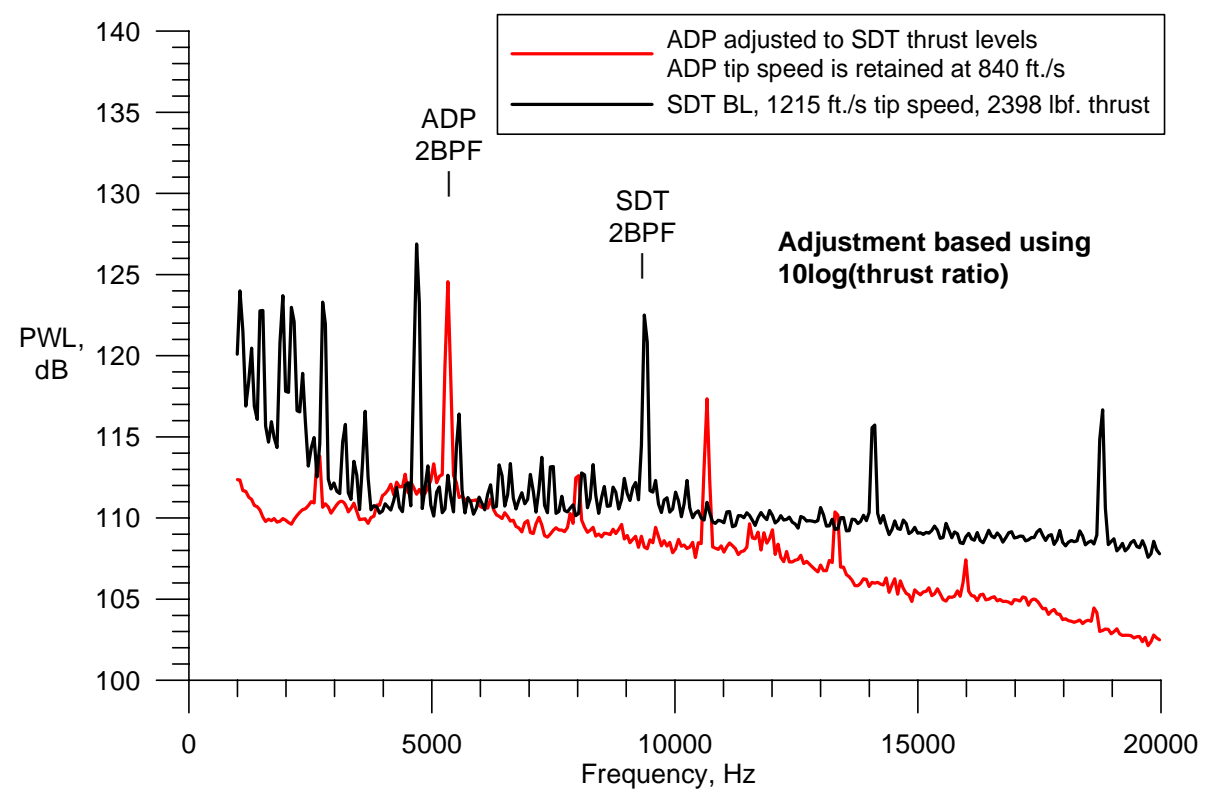

Figure 17. PWL spectra comparison of SDT (R4+baseline stator) at design speed, and ADP Fan1 using 10log(thrust ratio) to adjust ADP (design fan speed) noise to SDT thrust level.

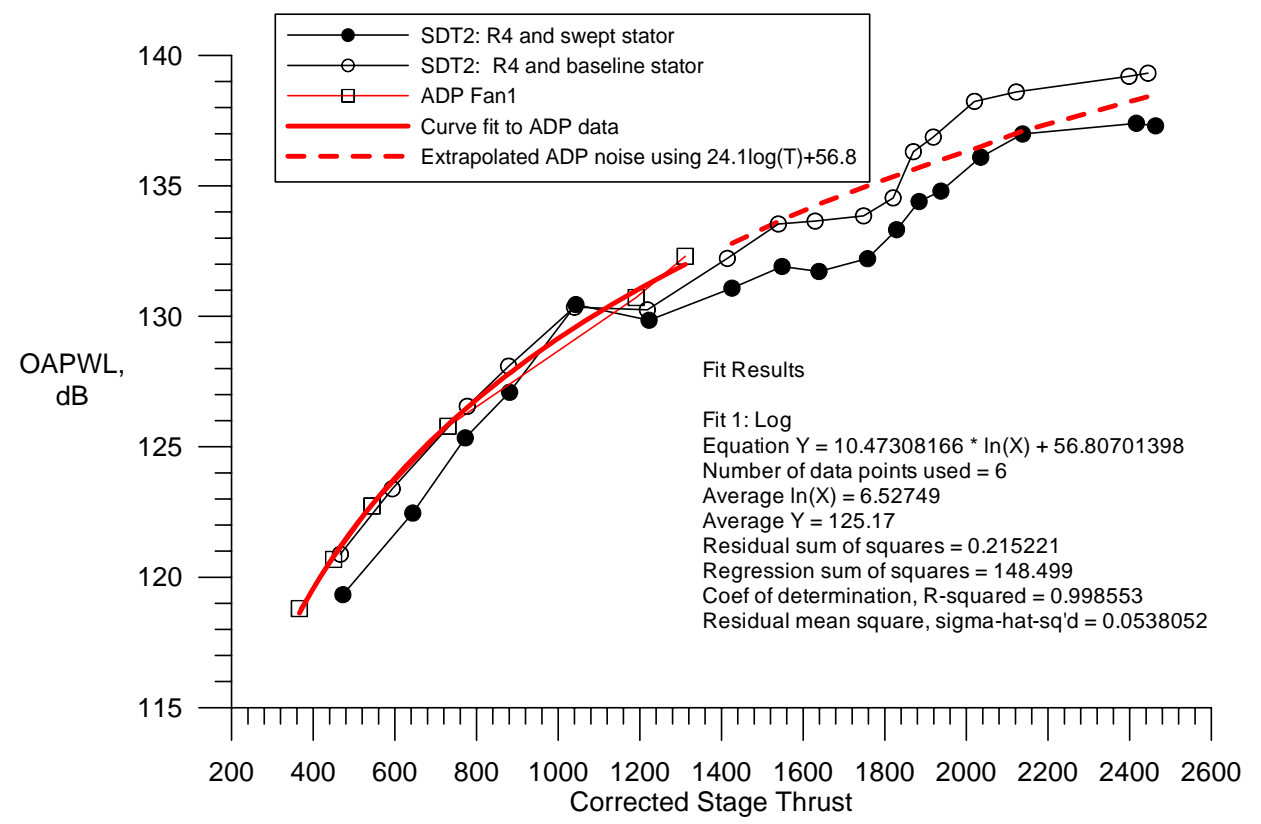

Figure 18. Example of logarithmic curve fit to ADP data to extrapolate noise data ((10log (thrust ratio) only valid for exact dimensional scaling of fan stage). 